\title{
Viral Diseases and Human Evolution
}

\section{Élcio de Souza Leal, Paolo Marinho de Andrade Zanotto ${ }^{+}$}

Laboratório de Evolução Molecular, Departamento de Microbiologia, Imunologia e Parasitologia, Universidade Federal de São Paulo, Rua Botucatu 862 - $8^{\circ}$ andar, 04023-062 São Paulo, SP, Brasil

The interaction of man with viral agents was possibly a key factor shaping human evolution, culture and civilization from its outset. Evidence of the effect of disease, since the early stages of human speciation, through pre-historical times to the present suggest that the types of viruses associated with man changed in time. As human populations progressed technologically, they grew in numbers and density. As a consequence different viruses found suitable conditions to thrive and establish long-lasting associations with man. Although not all viral agents cause disease and some may in fact be considered beneficial, the present situation of overpopulation, poverty and ecological inbalance may have devastating effets on human progress. Recently emerged diseases causing massive pandemics (eg., HIV-I and $\mathrm{HCV}$, dengue, etc.) are becoming formidable challenges, which may have a direct impact on the fate of our species.

Key words: molecular evolution - phylogeny - virus - human evolution

\section{THE EVOLUTIONARY BIOLOGY OF DISEASE}

The astonishing development of molecular and cell biology in recent years made possible a detailed study of the molecular genetics of host-parasite assemblages using the methodology of population genetics, molecular systematics, molecular epidemiology, etc. (Nei 1987, Hillis \& Moritz 1990, Li 1997, Page \& Holmes 1998). All these methodologies benefited from the Darwinian evolutionary thinking as an integrative framework (Maynard-Smith 1989, Brooks \& McLenann 1991, Gillespie 1991, Mayr 1994, Takahata 1994). Evolution deals with the change of genetic diversity in time and provides for an explanatory basis of crucial biological phenomena and processes (Dobzansky 1970). Due to its size and nature, viruses are directly studied at the cellular and subcellular levels. Therefore, virology has also been a major beneficiary of the evolutionary approach, which has recently started to renovate biomedical sciences (for a comprehensive review see Stearns 1999). A key concept is that, along with much of each lineage's own history, some of the history of virus-host escalation ("arms race") is kept in the genetic make-up of both contenders (i.e., Red Queen hypothesis, Van Valen 1973). This comes

ESL was funded by a Bristol-Myers Squibb grant and PMAZ by a PQ scholarship by CNPq.

${ }^{+}$Corresponding author. Fax: +55-11-3818.7354

E-mail: pzanotto@usp.br,pzanotto@uol.com.br

Received 7 August 2000

Accepted 4 September 2000 handy when dealing with situations where not much is known about a given virus, either because it was recently discovered, or because it just recently emerged or reemerged in humans. In this article a few aspects of the impact of viruses on human evolution will be addressed.

\section{THE IMPACT OF DISEASE FROM THE HUMAN ORIGIN}

The interaction of hosts and parasites may be a key factor in evolution, to the extent that basic features of biological systems such as the appearance of sex, may be explained by it (for a review see Hamilton et al. 1990). It is known that parasites are important factors regulating geographical distribution and host population size and density (for review and thorough mathematical treatment see Anderson \& May 1979a,b, 1991, May \& Anderson 1983; for an alternative perspective on the issue see Ewald 1994). It can also be postulated that man has been subject to infectious diseases throughout his evolutionary history (Fenner 1970, McKeown 1988). Infectious diseases that impact on man's life history parameters certainly did help creating further distinctions among the myriad of cultural configurations and, eventually, the way that many civilizations evolved.

Going back in evolutionary time, we still see evidence of the effect of disease in human evolution. The major histocompatibility complex (MHC) of humans and other primates constitute a multigene family which codes for proteins involved in tissue compatibility and immunological defense. Ayala et al. (1995) looked at the genetic diversity in the MHC array of genetic loci. Their interest was to estimate which polymorphism humans do 
share with chimpanzees and from it, the amount of polymorphism that was passed along from a putative ancestral species to us. Their work invites the conclusion that human speciation took place while maximizing the maintenance of the preexisting MHC polymorphism. Since MHC polymorphism does increase resistance to disease (Hill et al. 1991, 1992) it may be assumed that significant selective advantage was to be gained from keeping diversity at these loci during early human evolution. At least in part, this selective advantage had to be consequence of disease. Additionally, the persistence of MHC polymorphism during millions of years had interesting implications in the demographics of early man, since they implied that the size of the initial human effective population size $(\mathrm{Ne})$ had to be 100 thousand individuals or more (Ayala et al. 1995).

\section{THE DIASPORA}

Population genetics does suggest that the minimal population size of early man was under check by diseases. However, much more information is needed to unravel what the impact of disease was on shaping mankind, both biologically and socioculturally, from its onset until the recent recorded historical times (Black 1975, McNeill 1993). McNeill (1993) argued that when man left his cradle in tropical Africa around 50 to 100 thousand years before present (YBP), it left behind all but a few infestations and infections to which it had been exposed previously. Hare 1967, apud Black 1975, argued that the small size of prehistoric human communities would require that pathogens had to have the ability to multiply on alternative hosts or cause persistent infections in order to maintain lasting associations with man.

It is conceivable that when man moved out of Africa into more temperate climates, a significant shift took place on the types of challenges from disease it was exposed to. During the dispersal through all regions of the Earth (with the exception of a few islands), pathogens capable of causing persistent infections were possibly carried along. Conversely, pathogens requiring alternative hosts were purged once man left the geographical area of their alternative hosts and vectors. With the exception made for the couple last centuries, human historical records on specific diseases are scant and fragmentary, and do not allow a precise determination of the causative agents (McKeown 1988). In some instances paleopathologists were able to identify certain diseases that leave lesions in bones of primitive man, such as tuberculosis. Yet this approach does not suit the study of several diseases manifested only on soft tissues (Black 1975). At best, descriptive methods such as serology may provide identification of a disease agent and given optimal conditions, also inform on disease prevalence and incidence. For example, serological techniques introduced early in the 20th century allowed retrospective studies of seroprevalence and incidence in primitive societies (which may reflect the conditions of early man) and modern societies. These techniques provided not only fast identification of pathogens, even after clearance from the human host, but also their geographic distribution and some rough estimate of their genetic diversity and taxonomy. They also informed on whether a pathogen may cause recurrent disease, such as in those kept on alternative hosts with populations way larger than man's, since the proportion of seropositives increase with age (e.g., arboviruses and toxoplasmosis). Alternatively, age structuring of seropositivity in a community inform us on levels of endemicity or, whether pathogen is latent, sporadic or has recently being introduced (Black 1975). Until today serology remains a practical and useful basic research and clinical technique. Nevertheless, it may not be effective to gauge the amount of genetic variation directly caused by hostparasite interactions and therefore precludes a better understanding of the entailed evolutionary process.

Nowadays, modern genotyping technologies are giving considerable thrust to phylogenetic epidemiology of viruses, followed by the hallmark improvement of nucleic acid amplification attained by polymerase chain reaction (PCR) (Mullis \& Faloona 1987), thereby providing a potentially fast and easy assess to virus genetic information.

\section{HUMAN VIRUSES: ANCIENT AND NEW ASSO- CIATIONS}

Emerging or reemerging viruses are "new" diseases, which got our attention due to the fact that they may be associated with epidemic diseases of varying degrees of morbidity and mortality (Morse 1993, 1994). However, in several instances, it is possible that viruses may have crossed the specie's barrier recently, and started to propagate in explosive ways in the absence of known or proven causal association with manifested diseases. Hepatitis G virus being an example of the former instance (Pinho et al. 1999) and perhaps some human circoviruses (e.g., transfusion transmitted virus, TTV) of the latter.

In any case, it is possible that humans did not have many of the "modern" diseases such as measles, influenza, dengue, etc. until the Neolithic period, possibly because then the human population size and density were not enough to maintain sustained epidemics (Black 1975). As mentioned above, it is evident that before Neolithic times, vi- 
ruses capable to establish long term persistent infections in individuals had better chance to be maintained in human populations and be dispersed along with man. Among others, papilomaviruses, herpesviruses, hepatitis B and some retroviruses may constitute well studied examples of such longterm type of association. Papilomaviruses (HPV) are slow evolving DNA viruses which may cause persistent infections in humans. Its long lasting association with humans was investigated by Bernard (Chan et al. 1992, Ho et al. 1993, Ong et al. 1993). They presented molecular phylogenies which support the hypothesis that HPV came out of Africa and coevolved with distinct human ethnic groups ever since. Herpes are also slow evolving DNA viruses with large genomes (White \& Fenner 1986). Herpes viruses were shown to coevolve with distinct vertebrate lineages, possibly since the Devonian (McGeogh et al. 1995). Moreover, several present vertebrate lineages have their own "type" of herpes virus, which does not appear to have the capability to move across its hosts species barriers. Independent on whether they were introduced by Europeans or not, given the characteristics of its biology and evolutionary history, it is not surprising that three different herpes related viruses, namely, herpes simplex, Epstein-Barr and cytomegalovirus, along with hepatitis B (which also causes persistent infections) where found to be endemic in isolated primitive societies in the Amazon basin (reviewed by Black 1975). Hepatitis B viruses were found in ducks, woodchucks, squirrels and primates, suggesting a possible distant zoonotic origin for this virus as well (Takahashi et al. 2000), which could explain its endemic state in isolated Amazonian primitive societies.

Another interesting but potentially more complicated example is human T cell leukemia/lymphoma virus (HTLV) (Poiesz et al. 1980). The HTLV-1 also causes persistent infections in humans and the adjacency patterns in molecular phylogenies suggest that this virus is more related to the simian and primate $\mathrm{T}$ lymphotropic virus (STLV-1) isolated from Old World apes and monkeys in Africa (but apparently not from New World monkeys), than to HTLV-2, which also infects humans (for a review on the origin of HTLVs see Gessain \& Mahieux 1999). On the other hand, the HTLV-2 is found among several Indian populations throughout the Americas. As a consequence of this, it is called "Paleo-Amerindian" strain and it appears to be related to Asian isolates of STLV1. Nevertheless, the Asian origin of HTLV-2 is more obscure, since it was also found in several places in Africa and the molecular phylogenies of HTLV and STLV point to several independent instances of virus exchanges among primate species, including man (Gessain \& Mahieux 1999). The viruses we just mentioned above may exemplify strategies which may minimize morbidity and mortality and maximize viral survival at low host population density and numbers, yet we should avoid making sweeping generalizations on the issue of the evolution of virulence (for a review see Stearns 1999).

\section{ENDOGENOUS RETROVIRUSES AND HUMAN EVOLUTION}

Endogenous retroviruses (ERV) were until recently considered as part of "junk DNA". Yet, by being able to amplify their copy number by duplication and by being transmitted as Mendelian traits, they could have influenced the differences of genome size (C-value) observed among species with similar coding sequences (Lohman \& Bjornson 1996). Moreover, current data may indicate other relevant biological roles. The reason why so many of these elements lurk in our genome could entail some potential trade-off. In order to postulate this, a selective advantage for the abundance of exogenous retroviruses is needed. In fact, several instances where adaptive advantage may be postulated can be found.

A common characteristic of ERVs is the ability to generate multiple copies that can be integrated randomly or in clusters along the host DNA and at the sites of integration short repeats are created. Because ERV are involved in recombination and duplication events, they make possible gene duplication, allele diversity and polymorphism. This process probably influenced the level of diversity at polymorphic human genes, like MHC. Indeed, several HERV and HERV long terminal repeats have been found in MHC class II genes (Andersson et al. 1998); thereby, suggesting a possible beneficial role by increasing and maintaining allele polymorphism in this important gene family.

However, an intriguing potential impact of ERV on human evolution is to be appreciated under our recent understanding of gestation, brought by contemporary Darwinian thought. Following embryo implantation, placental macrophages will get in close contact with embryonic tissues, since the embryo has a distinct genetic make-up from that of the mother (Haig 1999). This genetic conflict can lead to the immune rejection of the embryo by the mother's immune system (as a matter of fact, most natural terminations take place very early during embryo formation). Certainly, it may also be related to several of the complications commonly observed during pregnancy.

A Darwinian view of the genetic conflict on pregnancy may provide not only satisfactory explanation for several common hardships encoun- 
tered during pregnancy, but it may also suggest another evolutionary trade-off between ERVs and humans. HERV-K10 and murine ERV transcripts expression are highly responsive to steroid hormones (Patience et al. 1997, Patience 1999), while high levels of ERV gene products are usually observed in primate placental (syncytiotrophoblastic) and embryonic cells (trophoblasts) (Boyd et al. 1993, Andersson et al. 1998). Therefore, it could be postulated that ERV gene expression could provide a transient immunosuppression early during pregnancy, which might be required to avoid embryo immune clearance (Villareal 1997).

The hypothesis of a transient immunosuppression during primate syncytiotrophoblast differentiation offers interesting clues of a possible significant adaptive advantage provided by endogenous retrovirus to the evolution of placental mammals. That is, human infection by ERVs may provide the temporary immune suppression crucial to embryo survival during early stages of pregnancy. Ultimately, it may counteract potential genetic conflict and thus may have played a role towards expansion of the genetic plasticity of human species.

\section{THE AGRICULTURAL REVOLUTION IN NEOLITHIC:} NEW DISEASES

Pathogens infecting primitive small isolated communities had to find ways (e.g. alternate host reservoirs, vertical transmission, persistence or latency, etc.) to keep alive, since the levels of susceptible human hosts during outbreaks would drop bellow that required to avoid the pathogen population to die out. Candidate viruses that possibly thrived since the agricultural revolution in the Neolithic up to recent historical times (when man established large-enough communities), were mainly those causing acute transient infections, such as respiratory viruses, measles, smallpox, etc. Accounts of the patterns of disease emergence in history consider the fact that, recently in evolutionary time, several human groups moved away from a hunter-gatherer stage by starting more complex agricultural practices, which entailed bigger communities living in longer lasting settlements (Black 1975, McKeown 1988, McNeill 1993).

This new human predicament had unforeseen ecological consequences, however. Besides ecological degradation, due to unsustainable economic practices and inadequate cultural configurations, another significant trade off was the inviting of new types of diseases. Given the increase in density and size of human communities, some pathogens started to find adequate conditions to establish lasting associations with man. Pests and other massive epidemics in historical time are possibly examples of this (McKeown 1988, McNeill 1993).

\section{VIRAL DISEASES IN THE HISTORICAL PAST}

Although we have good examples of viruses that reflect human history, the possible elucidation of the origin of most group of viruses, based on the biogeographical distribution of its genetic diversity, was made complicated by the increasing in the interconnections among human populations. The same could be said for almost any other known disease of the present. This was caused by the considerable exchange and movement of populations between the New and Old World, which took place since the outset of transoceanic navigations in the 16th century.

In fact, during the last few hundred years, due to this increasing mobility of humans made possible by transoceanic navigation and swift transcontinental migrations, viral diseases previously confined to specific geographical locations were able to spread widely, such as several arboviruses (e.g., dengue, yellow fever, etc.). The types of viruses that were able to move into the swelling human population certainly included those that cause lasting immunity among survivors including the smallpox, mumps, measles, etc. McNeill (1993) argued that once a local human population passed a threshold size, it was able to acquire a "epidemiological weapon" and that "the expanding endemically diseased society breaks down the political and cultural structure of peripheral, disease inexperienced populations". Moreover, he argued that disease would explain the small number of civilizations in Eurasia and the fact that today Africa still remains with Africans (with the exception of some land in the South).

One of the best examples of how a viral disease shaped history was the victory by barely vanquished Spaniards under Cortez over a much more formidable Aztec army in Mexico. The Aztecs, despite reaching superiority in the battle ground, causing the enemy to retreat, were hit by smallpox and, as a consequence, were eventually subdued. This event epitomized the fate of the indigenous populations and presented a recurrent pattern which lead to the repopulation of the Americas by disease-sturdy Europeans and Africans.

After the industrial revolution, man was able to achieve enough control over several technological processes, which caused mankind to mushroom in numbers. Over the last 200 years, mankind grew six times in size, reaching six billion by the end of the 20th century (Zanotto et al. 1996b). On top of that, fast and efficient means of transportation of humans and commodities across the planet, possibly helped several lineages of zoonotic viruses becoming mainly human diseases, bypassing a previously essential zoonotic cycle (Morse 1993, 
1994, Innis 1995). One of the most striking example of emergent diseases is the virus causing Aids (Gao et al. 1999). The HIV-1 has a relatively recent zoonotic origin. It is now believed that, after being associated with chimpanzees in Western Africa (Corbet et al. 2000), the HIV in half a century was able to infect millions of humans in the entire world (Zhu et al. 1999, Korber et al. 2000, for critical review on the pandemic see Gould 1993).

\section{WHAT CAN WE LEARN FROM THE MOLECULAR GENETICS OF VIRUSES}

In recent years, implementations on sequencing technologies made possible fast and easy access to the genetic sequence of pathogens, hence extending the study of the genetic diversity of viruses. Indeed, PCR screening coupled with sequencing has opened the possibility to either detect previously unknown but related members of established viral families, or even to detect new viruses. Sequence data was useful to the understanding of the ancestral relationships among viruses and to help address relevant questions about their possible origins (Zanotto et al. 1996a, Kossida et al. 2000). Moreover, sequence data of viral genomes, together with biogeographic information on host, vectors and diseases, have become a useful way to investigate dispersion mechanisms of new and emergent viruses. Sequence analysis showed a close relationship among the genetic material of various endogenous retroviruses and their natural hosts (Löwer et al. 1996, Herniou et al. 1998), thereby clarifying important questions concerning several aspects of the evolutionary biology of mammalian retroviruses. When not much is known about a newly identified virus, such as the hepatitis $\mathrm{G}$ virus, molecular phylogenies may help identifying contagion mechanisms (Pinho et al. 1999). The origin of viruses causing outbreaks may be readily identified by comparing their sequences with known references. This was the case of the Rift Valley Fever virus (RVFV) causing a recent massive outbreak in Kenya (Sall et al. 1998), or the unexpected appearance of the West Nile flavivirus in New York City last year (Lanciotti et al. 1999).

Molecular phylogenies may also help understanding a few interesting features of the life history of viruses, since they may represent the process of generation, loss and maintenance of the genetic diversity along its branches. Moreover, trees were shown to be explicit representation of gene substitution processes and were useful for estimating the selection coefficient of specific alleles in the nef gene of HIV-1 (Zanotto et al. 1999). Hepatitis $\mathrm{C}$ virus was identified almost ten years ago (Choo et al. 1989). Currently, it infects an estimated amount of 170 million people worldwide, yet despite a lack of previous records of the disease, we can estimate via the shape of phylogenetic trees, possible times when it entered the human population (Holmes 1996). On another instance, distinctions in the biology of tick- and mosquito-borne flaviviruses were also made apparent due to characteristics of their phylogenetic trees. Tick-borne encephalitis (TBE) viruses have a highly asymmetric and pectinated phylogeny indicative of a clinal distribution (that is, a geneticgeographic continuum) over much of Central and Western Europe. This possibly reflects the dispersion of the vector species (Zanotto et al. 1995). Mosquito borne flaviviruses, on their turn, are cosmopolitan due to the worldwide distribution of the mosquito vector species. They also show molecular phylogenies that reflect their recent increasing interaction with the human population. Dengue viruses causing the current pandemics, appear to have been subjected to a recent increase in its genetic diversity. This can be inferred by phylogenetic trees constructed on the sequence data of their envelope gene. Those trees showed few ancestral lineages but revealed a recent exponential increase in the number of lineages (Zanotto et al. 1996b). This was explained merely by the explosive human population growth during the last 200 years (Zanotto et al. 1996b, Holland 1996). Molecular phylogenies may also provide means of mapping specific amino acid replacements during the succession of endemic influenza strains, possibly caused by the immune selection of the human populations (Fitch et al. 1991). They were also used to elucidate transmission webs of HIV-1 in epidemic clusters and support forensic arguments about HIV1 transmission cases (Holmes et al. 1993).

Several new developments in population genetics applied to the study of viruses, promise to change the field in further dramatic ways. Viruses are now been used as models for evolutionary biology in experimental evolutionary work, since empirically generated known molecular phylogenies of viruses have the potential to enhance inferential methodology (Hillis et al. 1992). Moreover, given the speed of some viral populational processes and technical convenience (millions of individual viruses replicating very fast in milliliter-sized flasks), several aspects of classical evolutionary models are being tested by using viruses (Burch \& Chao 1999). The long-lasting debate on selectionism and neutralism (Gillespie 1991, Golding 1994, Kimura 1994, Hey 1999) may also see considerable progress, due to the use of viruses as experimental models (Leigh Brown 1997, Rouzine \& Coffin 1999a,b, Zanotto et al. 1999). It 
is fair to postulate that viruses may have a similar impact on evolutionary biology in the 21 st century, as fruit flies had during the early 20th century.

\section{FUTURE PERSPECTIVES: MAN IN BALANCE}

Our understanding of emerging and reemerging viruses from an evolutionary perspective offers clear directions to follow. Firstly, if we seriously plan to come up with efficient and reasonable control strategies, an international concerted effort on a thorough survey of the genetic diversity, in time and space of viruses is a must. This will also help understanding several processes that take place at the molecular level in a comparative context (Harvey \& Pagel 1991). Secondly, more emphasis on multidisciplinary sciences is needed. Molecular biology and systematics, bioinformatics, data mining and analysis, etc., all are becoming considerably sophisticated lately. However, these endeavors will be more effective only when developed and applied on integrative research programs with strong empirical backing.

It is common sense to understand human disease as caused by man himself. Among its key factors we can cite: ecological degradation, poverty and human conflict. Even when massive wealth and technological progress takes place among some, disease persists for most. Technically, this can be explained by historical (cultural) inheritance and huge differences among the many civilizatory stages of present day societies (many of which may not survive under a single or imposed paradigm of development). However, the Darwinian understanding of our biological origin and constitutive traits begs for a critical reflection upon our future.

Ultimately, the present appalling state of affairs for billions of human beings can only be surpassed by compassionate understanding of our collective human condition and fate, at the expense of blind short-term circumstantial advantages. Hepatitis C and HIV-1 are glaring proofs that disease knows no national borders. Solutions for the problems of diseased poor societies are not only the most humane universal priority but, possibly also a guarantee for the future generations and ultimately for the survival of man as a species.

\section{REFERENCES}

Anderson RM, May RM 1979a. Population biology of infectious diseases: part I. Nature 280: 361-367.

Anderson RM, May RM 1979b. Population biology of infectious diseases: part II. Nature 280: 455-460.

Anderson RM, May RM 1991. Infectious Diseases of Human. Dynamics and Control, Oxford University Press, Oxford, $757 \mathrm{pp}$.

Andersson G, Svensson AC, Stterblad N, Rask L 1998.
Retroelements in the human MHC class II region. Trends Genet 14: 109-113.

Ayala FJ, Ananías E, O’Huigin C, Klein J 1995. Molecular genetics of speciation and human origins. In WM Fitch, FJ Ayala (eds), Tempo and Mode in Evolution. Genetics and Paleontology 50 Years after Simpson, National Academy Press, Washington, p. 187-211.

Black FL 1975. Infectious diseases in primitive societies. Science 187: 515-518.

Boyd MT, Bax CM, Bax BE, Bloxam DL, Weiss RA 1993. The human endogenous retrovirus ERV-3 is upregulated in differenting placental trophoblast cells. Virology 196: 905-909.

Brooks DR, McLennan DA 1991. Phylogeny, Ecology and Behaviour, Chicago University Press, Chicago, $435 \mathrm{pp}$.

Burch CL, Chao L 1999. Evolution by small steps and rugged landscapes in the RNA virus F6. Genetics 151: 921-927.

Chan SY, Bernard HU, Ong CK, Chan SP, Hofmann B, Delius H 1992. Phylogenetic analysis of 48 papillomavirus types and 28 subtypes and variants: a showcase for the molecular evolution of DNA viruses. J Virol 66: 5714-5725.

Choo QL, Kuo G, Weiner AJ, Lacy R, Overby LR, Bradley DW, Houghton M 1989. Isolation of a cDNA clone derived from a blood-borne non-a, non-b viral hepatitis genome. Science 244: 359-362.

Corbet S, Muller-Trutwin MC, Versmisse P, Dealrue S, Ayouba A, Lewis J, Brunak S, Martin P, BrunVezianet F, Simon F, Barre-Sinoussi F, Mauclere P 2000. env sequences of simian immunodeficiency viruses from chimpanzees in Cameroon are strongly related to those of human immunodeficiency virus group $\mathrm{N}$ from the same geographic area. $J$ Virol 74: 529-534.

Dobzhansky T 1970. Genetics of the Evolutionary Process, Columbia University Press, New York, $505 \mathrm{pp}$.

Ewald PW 1994. Evolution of Infectious Diseases, Oxford University Press, Oxford, 298 pp.

Fenner F 1970. In SV Boyden, The Impact of Civilization on the Biology of Man, University of Toronto Press, Toronto, $266 \mathrm{pp}$.

Fitch WM, Leiter JME, LI X, Palese P 1991. Positive Darwinian evolution in human influenza A viruses. Proc Natl Acad of Sci USA 88: 4270-4274.

Gao F, Bailes E, Robertson DL, Chen Y, Rodenburg CM, Michael SF, Cummins LB, Arthur LO, Peeters M, Shaw GM, Sharp PM, Hahn BH 1999. Origin of HIV-1 in the chimpanzee Pan troglodytes troglodytes. Nature 397: 463-441.

Gessain A, Mahieux R 1999. Genetic diversity and molecular epidemiology of primate $\mathrm{T}$ cell leukaemia/ lymphoma viruses types 1 and 2 and related simian retroviruses (STLV-1, STLV-2, PAN-P and PTLVL). In AG Dalgleish, RA Weiss (eds), HIV and the New Viruses, 2nd ed., Academic Press, New York, p. 281-323.

Gillespie JH 1991. The Causes of Molecular Evolution, Oxford Series in Ecology and Evolution, Oxford University Press, Oxford, 336 pp. 
Golding B 1994. Non-neutral Evolution. Theories and Molecular Data, Chapman \& Hill, New York, 250 pp.

Gould P 1993. The Slow Plague. A Geography of the AIDS pandemics, Blackwell Publishers, Cambridge, MA, 228 pp.

Haig D 1999. Genetic conflicts of pregnancy and childhood. In SC Stearns, Evolution in Health and Disease, Oxford University Press, Oxford, p. 77-89.

Hamilton WD, Axelrod R, Tanese R 1990. Sexual reproduction as an adaptation to resist parasites (a review). Proc Natl Acad Sci USA 87: 3566-3573.

Harvey PH, Pagel MD 1991. The Comparative Method in Evolutionary Biology, Oxford Series in Ecology and Evolution, Oxford University Press, Oxford, 239 pp.

Herniou E, Martin J, Miller K, Cook J, Wilkinson M, Tristem M 1998. Retroviral diversity and distribution in vertebrates. $J$ Virol 72: 5955-5965.

Hey J 1999. The neutralist, the fly and the selecionist. Tree 14: 35-38.

Hillis DM, Moritz C 1990. Molecular Systematics, Sianuer Associates, Inc., Publishers, Sunderland, MA, 588 pp.

Hill AVS, Allsopp CEM, Kwiatowski D, Anstey NM, Twumasi P, Rowe PA, Bennett S, Brewster D, McMichael AJ, Greenwood BM 1991. Common West African HLA antigens are associated with protection from severe malaria. Nature 352: 595-600.

Hill AVS, Kwiatowski D, McMichael AJ, Greenwood BM, Bennett S 1992. Maintenance of MHC polymorphism. Nature 355: 402-403.

Hillis DM, Bull JJ, White ME, Badgett MR, Molineux IJ 1992. Experimental phylogenetics: generation of a known phylogeny. Science 255: 589-592.

Ho L, Chan SY, Burk RD, Das BC, Fujinaga K, Icenogle JP, Kahn T, Kiviat N, Lancaster W, MavromaraNazos P, Labropoulou V, Mitrani-Rosenbaum S, Norrild B, Pillai RM, Stoerker J, Syrjaenen K, Syrjaenen S, Tay SK, Villa LP, Wheeler CM, Williamson AL, Bernard HU 1993a. The genetic drift of human papillomavirus type 16 is a means of reconstructing prehistoric viral spread and the movement of ancient human populations. J Virol 67: 64136423.

Holland JJ 1996. Evolving virus plagues. Proc Natl Acad Sci USA 93: 545.

Holmes EC 1996. Reconstructing the history of viral epidemics. Biologist 43: 54-57.

Holmes EC, Leigh Brown AJ, Simmonds P 1993. Sequence data as evidences. Nature 364: 766.

Innis F 1995. Dengue and hemorragic fever. In J Porterfield, Exotic Viral Infections. Kass Handbook of Infectious Diseases, Chapman and Hall Medical Editions, London, 225 pp.

Kimura M 1994. Population genetics, molecular evolution, and the neutral theory. In Motoo Kimura, N Takahata, Selected Papers, The University of Chicago Press, Chicago, 686 pp.

Korber B, Muldoon M, Theiler J, Gao F, Gupta R, Lapedes A, Hahn BH, Wolinsky S, Bhattacharya T 2000. Timing the ancestor of the HIV-1 pandemic strains. Science 288: 1789-1796.

Kossida S, Harvey PH, Zanotto PMA, Charleston M 2000. Lack for evidence for cospeciation between retroelements and their hosts. J Mol Evol 50: 194201.

Lanciotti RS, Roehrig JT, Deubel V, Smith J, Parker M, Steele K, Crise B, Volpe KE, Crabtree MB, Scherret JH, Hall RA, MacKenzie JS, Cropp CB, Panigrahy B, Ostlund E, Scmitt B, Malkinson M, Banet C, Weissman J, Komar N, Savage HM, Stone W, MacNamara T, Gubler DJ 1999. Origin of the West Nile virus responsible for an outbreak of encephalitis in the northeastern United States. Science 286: 2333-2337.

Leigh Brown AJ 1997. Analysis of HIV-1 env gene sequences reveals evidence for a low effective number in the viral population. Proc Natl Acad Sci USA 94: 1862-1865.

Li WH 1997. Molecular Evolution, Sianuer Associates, Inc., Sunderland, MA, 487 pp.

Lohman TM, Bjornson KP 1996. Mechanisms of helicase-catalyzed DNA unwinding. Annu Rev Biochem 65: 169-214.

Löwer R, Löwer J, Kurth R 1996. The viruses in all of us: characteristics and biological significance of human endogenous retrovirus sequences. Proc Natl Acad Sci USA 93: 5177-5184.

Maynard-Smith J 1989. Evolutionary Genetics, Oxford University Press, Oxford, 325 pp.

May RM, Anderson RM 1983. Epidemiology and genetics in the coevolution of parasites and hosts. Proc $R$ Soc London B 219: 281-313.

Mayr E 1994. Driving forces in evolution: an analysis of natural selection. In SS Morse, The Evolutionary Biology of Viruses, Raven Press, New York, p. 2948.

McGeoch DJ, Cook S, Dolan A, Jamieson FE, Telford EAR 1995. Molecular phylogeny and evolutionary timescale for the family of mammalian herpesviruses. J Mol Biol 247: 443-458.

McKeown T 1988. The Origin of Human Disease, Blackwell Publishers Ltd., Oxford, 233 pp.

McNeill WH 1993. Patterns of disease emergence in history. In SS Morse, Emerging Viruses, Oxford University Press, Oxford, p. 29-36.

Morse SS 1993. Examing the origins of emerging viruses. In SS Morse, Emerging Viruses, Oxford University Press, Oxford, p. 10-36.

Morse SS 1994. The viruses of the future? Emerging viruses and evolution. In SS Morse, The Evolutionary Biology of Viruses, Raven Press, Ltd., New York, p. 325-340.

Mullis KB, Faloona FA 1987. In R Wu, Methods in Enzymology, Academic Press, Inc., London, p. 335.

Nei M 1987. Molecular Evolutionary Genetics, Columbia University Press, New York, 512 pp.

Ong CK, Chan SY, Campo SM, Fijinaga K, MavromaraNazos P, Labropoulou V, Pfister H, Tay SK, Meulen J, Villa LP, Bernard HU 1993b. Evolution of human papillomavirus type 18: an ancient phylogenetic root in Africa and intratype diversity reflected coevolution with human ethnic groups. J Virol 67: 
6424-6431.

Page RDM, Holmes EC 1998. Molecular Evolution: a Phylogenetic Approach, Blackwell Science, London, $346 \mathrm{pp}$.

Patience C 1999. Endogenous retroviruses. In AG Dangleish, RA Weiss (eds), HIV and New Viruses, Academic Press, p. 485-497.

Patience C, Wilkinson DA, Weiss RA 1997. Our retrovirus heritage. Trends Genet 13: 116-120.

Pinho JRR, Zanotto PMA, Ferreira JL, Sumita LM, Carrilho FJ, da Silva LC, Capacci ML, Silva AO, Guz B, Gonçales FL, Gonçales NS, Buck GA, Meyers GA, Bernardini AP 1999. GB Virus C: high prevalence among Brazilian blood donors and molecular evidence for intrafamilial transmission. J Clin Microbiol 37: 1634-1637.

Poiesz BJ, Ruscetti FW, Gazdar AF, Bunn PA, Minna JD, Gallo RC 1980. Detection and isolation of type $\mathrm{C}$ retrovirus particles from fresh and cultured lymphocytes of a patient with cutaneous T-cell lymphoma. Proc Natl Acad Sci USA 77: 7415-7419.

Rouzine IM, Coffin JM 1999a. Linkage disequilibrium test implies a large effective population number for HIV in vivo. Proc Natl Acad Sci USA 96: 1075810763.

Rouzine IM, Coffin JM 1999b. Search for the mechanism of genetic variation in the pro gene of human immunodeficiency virus. J Virol 73: 8167-8178.

Sall AA, Zanotto PMA, Vialat P, Sene OK, Bouloy M 1998. The origin of Rift Valley fever virus causing the 1998 outbreak in East Africa. Lancet 14: 15961597.

Stearns SC 1999. Evolution in Health and Disease,
Oxford University Press, Oxford, 328 pp.

Takahata N 1994. Repeated failures that led to the eventual success in human evolution. Mol Biol 11: 803805.

Takahashi K, Brotman B, Usuda S, Mishiro S, Prince AM 2000. Full-genome sequence analyses of hepatitis B virus (HBV) strains recovered from chimpanzees infected in the wild: implications for an origin of HBV. Virology 267: 58-64.

Van Valen L 1973. A new evolutionary law. Evol Theory 1: $1-30$.

Villareal LP 1997. On viruses, sex, and motherhood. $J$ Virol 71: 859-864.

White DO, Fenner SJ 1986. Medical Virology, 3rd ed., Academic Press, Inc., Orlando, FA, 655 pp.

Zanotto PMA, Gao GF, Gritsun T, Marin MS, Jiang WR, Venugopal K, Reid HW, Gould EA 1995. An arbovirus cline across the northern hemisphere. Virology 210: 152-159.

Zanotto PMA, Gibbs MJ, Gould EA, Holmes EC 1996a. A reevaluation of the higher taxonomy of virus based on RNA polymerases. J Virol 70: 6083-6096.

Zanotto PMA, Gould EA, Gao GF, Harvey PH, Holmes EC 1996b. Population dynamics of flaviviruses revealed by molecular phylogenies. Proc Natl Acad Sci USA 93: 548-553.

Zanotto PMA, Kallas EG, Souza RF, Holmes EC 1999. Evidence for positive selection in the nef gene of HIV-1. Genetics 153: 1077-1089.

Zhu T, Korber BT, Nahmias AJ, Hooper E, Sharp PM, Ho DD 1999. An African HIV-1 sequence from 1959 and implications for the origin of the epidemic. Nature 391: 594-597. 